\title{
Improving Graduation Rates in Drug Court through Employment and Schooling Opportunities and Medication-Assisted Treatment (MAT)
}

John Robert Gallagher, PhD, LSW, LCAC

Associate Professor, School of Social Work

Indiana University South Bend (IUSB)

(574) 514-1813

johngall@iupui.edu

Elizabeth A. Wahler, PhD

MSW Program Director/Assistant Professor, School of Social Work

Indiana University Purdue University Indianapolis (IUPUI)

bwahler@iupui.edu

Elyse Lefebvre, MSW

Graduate Research Assistant, School of Social Work

Indiana University South Bend (IUSB)

elefebvr@imail.iu.edu

Tara Paiano, BS

Drug Court Coordinator

St. Joseph County (Indiana) Drug Court

TPaiano@co-st.joseph.in.us

Jesse Carlton, BA

Chief Probation Officer

St. Joseph County (Indiana) Adult Probation

jcarlton@co.st-joseph.in.us

Honorable Jane Woodward Miller, JD

Drug Court Judge

St. Joseph County (Indiana) Drug Court

JMiller@,co.st-joseph.in.us

This is the author's manuscript of the article published in final edited form as:

Gallagher, J. R., Wahler, E. A., Lefebvre, E., Paiano, T., Carlton, J., \& Miller, J. W. (2018). Improving Graduation Rates in Drug Court Through Employment and Schooling Opportunities and Medication-Assisted Treatment (MAT). Journal of Social Service Research, 44(3), 343-349. https://doi.org/10.1080/01488376.2018.1472173 


\section{Improving Graduation Rates in Drug Court through Employment and Schooling Opportunities and Medication-Assisted Treatment (MAT)}

Drug courts have been a key part of the criminal justice system since 1989, and this study contributes to the existing body of research by identifying which participants $(n=248)$ were most likely to graduate from a drug court in Indiana (United States). Three variables emerged as significant predictors of graduation. First, participants who were employed or were students at the time of admission were nearly 2.5 times more likely to graduate than participants who were not. Second, participants who were using opiates as their primary drug of choice were over $80 \%$ less likely to graduate than participants who were using non-opiates as their primary drug of choice. Third, participants who had violations in the first 30 days of the program were nearly $50 \%$ less likely to graduate than participants who did not violate in the first 30 days. Offering medicationassisted treatment (MAT), such as methadone, Suboxone, or Vivitrol, to participants who have an opiate use disorder may improve graduation rates for this population. Additionally, graduation rates may also improve by offering more resources to assist participants in gaining and maintaining employment or schooling, and this seems to be especially important within the first month of the program.

Keywords: criminal recidivism, drug court, employment, graduation, medication-assisted treatment (MAT), substance use disorder 


\section{Introduction}

Drug courts have been a key part of the criminal justice system since 1989, and they continue to increase throughout the United States and internationally. Drug courts are located in all 50 United States and United States territories and total over 3,000 (National Association of Drug Court Professionals [NADCP], 2017). Drug courts are largely a movement in the United States; however, global expansion of these programs, presumably due to their success at reducing criminal recidivism, has occurred and they can now be found in Australia, Belgium, Brazil, Canada, Ireland, Jamaica, Mexico, Norway, and Scotland, to name a few (International Association of Drug Treatment Courts [IADTC], 2017). As drug courts continue to expand inside and outside the United States, ongoing evaluation is important to develop and in-depth understanding of who benefits most from drug court by graduating, as often graduates have their criminal case(s) dismissed and are less likely to recidivate than those who are terminated from the program (Gallagher, 2014).

The overall goal of drug courts is to reduce the criminal recidivism rate for nonviolent offenders who have a substance use disorder, and meta-analyses have suggested that drug courts are more effective than traditional criminal justice interventions, such as probation, at meeting this goal (Mitchell, Wilson, Eggers, \& MacKenzie, 2012; Shaffer, 2011). Drug court are conceptualized through ten key components, and these key components are designed to offer a rehabilitative approach in treating substance use disorders, while also promoting individual accountability for change and public safety (NADCP, 2004). Key components, for example, of the drug court model include participants having frequent, usually weekly or biweekly, contact with the judge to provide an update on their progress in the program, submitting drug screens, approximately 2 to 3 times a week, on a random basis, and participating in treatment for their 
substance use disorders and other ancillary interventions, such as vocational rehabilitation or educational services, when needed (NADCP, 2004). In addition, the drug court professionals are responsibility for implementing the key components. Judges, prosecuting and defense attorneys, counselors, and case managers or probation officers, for instance, are required to attend trainings on best practices in the drug court model and to interact with participants in a non-adversarial manner (NADCP, 2004). Drug courts, also, are required to evaluate their programs to assess if they are meeting their intended outcomes, which may include cost-effectiveness analyses, longitudinal studies, or, as presented in this study, identify predictors of graduation (NADCP, 2004).

Previous research, although not surprising, has suggested that older participants, those who have more education, and those who are employed or students are more likely to graduate than their counterparts are. In the Salt Lake City, Utah drug court, researchers found that older participants were more likely to graduate than younger participants were; spending free time with family rather than friends was also a significant predictor of graduation (Hickert, Boyle, \& Tollefson, 2009). In a recent evaluation, Gill (2016) found that education status was the largest predictor of drug court outcome, with participants who did not have a high school diploma or GED being 2.6 times more likely to not graduate from drug court than participants who had a high school diploma or GED. In a Texas drug court, participants who were employed or were students at the time of admission were nearly 5 times more likely to graduate than participants who not employed or students at admission (Gallagher, 2013b).

Race and ethnicity is another important variable used to predict graduation from drug court. Some drug courts have found racial disparities in graduation rates where minority participants were less likely to graduate than their White counterparts (Gallagher, 2013b; 
Marlowe, 2013). In a Texas drug court, for instance, $65.42 \%$ of White participants graduated the program, whereas the graduation rate for Hispanics was $52.17 \%$ and for African Americans was 45.71\% (Gallagher, 2013b). A possible explanation for this phenomenon is that minority participants may be underrepresented in some drug courts (Marlowe, 2013), and Gallagher (2013a) found in his qualitative study that African American participants felt they would graduate drug court more frequently if there were more African Americans in the program, perhaps because this would enhance camaraderie and peer support.

This phenomenon, however, is more complex than simply the representation of individuals in drug court. When comparing the graduation rates between just White and African American drug court participants, Dannerbeck, Harris, Sundet, and Lloyd (2006) found that 55\% of White participants graduated drug court, compared to only $28 \%$ of African Americans who graduated. Possible explanations for this racial disparity in graduation rates was that African Americans were more likely than White participants to be unemployed when they started drug court, identify cocaine as their drug of choice, and be classified as having low community status, which was a variable that combined data related to income, adequacy to housing, neighborhood environment, and employment classification (Dannerbeck et al., 2006).

As drug courts continue to expand globally, it is important that evaluations continue to add to the existing knowledge base on who benefits most from drug courts. Moreover, as mentioned previously, evaluations are necessary and required as a key component of all drug courts to assess if intended outcomes are being achieved or not. This study contributes to the existing literature by evaluating an Indiana (United States) drug court to identify who is most likely to graduate the program. Understanding the variables that impact graduate rates is especially important because research has consistently demonstrated that participants who 
graduate drug court are less likely to recidivate than those who are terminated from the program (Gallagher, 2014; Gallagher, Ivory, Carlton, \& Woodward Miller, 2014).

\section{Methodology}

\section{Data Collection and Sample Size}

This study was approved by an Institutional Review Board (IRB). This study has one research question: Who is most likely to graduate drug court? The drug court for this study was located in a metropolitan area in Indiana (United States) and the county population was approximately 270,000 . To answer the research question, data were collected on all participants $(n=248)$ who started the drug court from 2010 to 2015 and either graduated or were terminated from the program. Data were collected through the electronic charts of each participant. The sample size of 248 is justified for this study. Orme and Combs-Orme (2009), for example, suggest that a sample size of at least 100 be used when doing hierarchical binary logistic regression that has ten or fewer independent variables. This study has ten independent variables, and the dependent variable is drug court outcome $(0=$ terminated, $1=$ graduated $)$.

\section{Approach to Analysis}

Before multivariate analysis, data were screened to check for missing data and potential violations of assumptions. One variable, the number of days between arrest and admission to drug court, had two outliers. Over $99 \%$ of the sample reported being admitted to drug court between 16 and 646 days after arrest, but two participants reported 1642 and 1920 days. Thus, responses for this variable were capped at 646 for the statistical analyses. See Table 1 for coding scheme and descriptive statistics for model variables. T-tests and chi-square analyses were then utilized to examine bivariate relationships between drug court graduation and all model variables. 
The primary analysis was then conducted using hierarchical binary logistic regression. A hierarchical model was tested in order to detect the specific impact of blocks of variables on the outcome variable. The first model examined how individual characteristics, including gender, race/ethnicity, age, education level, and employment status predicted drug court outcomes. The second model examined how the addition of other clinically relevant variables, including primary drug of addiction (opiate versus non-opiate), mental health (previous mental health diagnosis or none), number of days between arrest and admission to drug court, and criminal history (previous misdemeanor or felony case prior to the current charge or none) increased the ability to predict drug court graduation. Whether or not there was a drug court violation (dilute drug test, positive drug test indicating new use, missed treatment or drug court appointment, or new arrest) in the first 30 days in the program was added to the third model to determine whether that variable improved the ability to predict drug court graduation. All statistical analyses were performed using SPSS 24.0.

[Insert Table 1 about here]

\section{Findings}

\section{Bivariate Relationships}

Bivariate relationships between the drug court outcome variable (graduated versus terminated) and all other model variables were examined using t-tests and chi-square analyses, as noted in Table 2. Variables significantly associated with drug court graduation were employment status, primary drug of addiction, having a previous criminal case, and having a violation within the first 30 days of drug court. Participants who were employed or were students at the time of admission were more likely to graduate than participants who were not $\left(74.4 \%\right.$ versus $\left.52.0 \%, \chi^{2}=13.35, p \leq .001\right)$. Participants who were using opiates as their primary 
drug were less likely to graduate than participants who had other primary drugs of addiction $\left(30.0 \%\right.$ versus $\left.69.7 \%, \chi^{2}=22.78, p \leq .001\right)$. Participants with previous criminal cases and those who had violations in the first 30 days of the program were less likely to successfully graduate than participants with no previous criminal case or those who did not violate in the first 30 days $\left(51.0 \%\right.$ versus $66.3 \%, \chi^{2}=3.97, p=.05$ and $57.7 \%$ versus $\left.70.8 \%, \chi^{2}=4.42, p=.04\right)$.

[Insert Table 2 about here]

\section{Model Fit}

Statistics demonstrating model fit were examined before interpreting coefficients (see Table 3). The -2 Log Likelihood values decreased from 308.60 in the first model to 284.46 in the third model, indicating improvement of fit with each subsequent model tested. The Omnibus $\chi^{2}$ for each model was significant and increased with each subsequent model. The Nagelkerke pseudo- $\mathrm{R}^{2}$ value increased with each subsequent model and indicated that the final model accounted for approximately one-fifth of the variance in the dependent variable (Nagelkerke $\mathrm{R}^{2}=$ .21). In addition, the hit rate improved with each subsequent model, increasing from $63.3 \%$ to $70.6 \%$ with all variables included in the final model. Notably, the final model was better at predicting which participants would graduate from drug court than it was at predicting people who were terminated from the program (87.9\% correctly classified versus $40.7 \%)$.

[Insert Table 3 about here]

\section{Summary of model variables}

Personal characteristics, including gender, race/ethnicity, age, education level, and employment status, were entered in the first model (see Table 3). This block of variables resulted in a Nagelkerke $\mathrm{R}^{2}$ of .09 . The only variable that was significant was employment status. Participants who were employed or were students at the time of admission were nearly 
2.8 times as likely to successfully graduate from drug court than participants who were unemployed or not in school $\left(\operatorname{Exp}(B)=2.77\right.$, Wald $\left.\chi^{2}=12.89, \mathrm{p} \leq .001\right)$.

The other potentially clinically relevant variables (opiate versus non-opiate primary drug of addition, mental health diagnosis, number of days between arrest and admission to drug court, and criminal history) were added in the second model. Employment status remained significant $\left(\operatorname{Exp}(B)=2.44\right.$, Wald $\left.\chi^{2}=8.75, p=.003\right)$, and participants who were employed or were students were nearly 2.5 times as likely to graduate drug court than participants who were unemployed or not in school. Drug of addiction was also significant $\left(\operatorname{Exp}(B)=.18\right.$, Wald $\left.\chi^{2}=15.57, p \leq .001\right)$; participants who primarily used opiates prior to drug court were over $80 \%$ less likely to graduate than participants who had a non-opiate primary drug of addiction. With the addition of these variables in the model, the Nagelkerke $\mathrm{R}^{2}$ increased to .19 .

Finally, the third model was tested which included the addition of whether or not participants had a drug court violation in the first 30 days of the program as a predictor. Employment status and primary drug of addiction maintained significance in this model, with odds ratios for graduation rate by employment status $(\operatorname{Exp}(B)=2.47)$ and opiate drug of addiction $(\operatorname{Exp}(B)=.17)$ remaining consistent with the previous model. Whether or not participants had violated in the first 30 days was also significant in this model $(\operatorname{Exp}(B)=.51$, Wald $\chi^{2}=5.05, p=.03$ ). If participants had a drug court violation in the first 30 days of the program, they were nearly $50 \%$ less likely to graduate than participants who did not have a violation during that timeframe. The final Nagelkerke $\mathrm{R}^{2}$ was .21 .

\section{Limitations}

There are several limitations with this research design that are important to mention. First, the final model only accounted for about $21 \%$ of the variance in graduation and was better 
at predicting graduates versus participants who were terminated from drug court. This implies that there are other variables that account for much of the variance in graduate rate. Therefore, it is recommended that future research explore what these variables may be, including level of income, family support, criminal thinking patterns, motivation for change, access to community resources, such as healthcare, to name a few. Second, the findings from this study should be interpreted with caution when used to inform drug court practice. While the findings are specific to the drug court evaluated in this study, not every drug court operates in the same manner. Therefore, the findings may not be generalizable. Some drug courts, for example, may have a low rate of participants that identify opiates as their drug of choice, but a higher rate of other drugs of choice, such as methamphetamine. Only through individual program evaluations will drug courts be able to identify the predictors of graduation for their specific programs.

\section{Discussion}

Findings from the hierarchical binary logistic regression revealed that three variables emerged as significant predictors of graduation. First, participants who were employed or were students at the time of admission were nearly 2.5 times more likely to graduate than participants who were not. This finding is consistent with previous research. In a Texas drug court, for example, participants who were employed or were students at the start of drug court were nearly 5 times more likely to graduate than their counterparts (Gallagher, 2013b). Being employment, in particular, has consistently increased the likelihood of drug court participants having increased graduation rates and reduced recidivism rates (Dannerbeck et al., 2006; Gallagher et al., 2015; Goldkamp, 1994; Listwan, Shaffer, \& Hartman, 2009; Mullany \& Peat, 2008; Peters \& Murrin, 2000). 
Second, participants who had violations in the first 30 days of the program were nearly $50 \%$ less likely to graduate than participants who did not violate in the first 30 days. This variable is not commonly measured in drug court evaluation. The few studies, however, that have assessed participants' compliance within the first month of drug court have found that those with better compliance are more likely to graduate (Gallagher et al., 2015; Newton-Taylor, Patra, \& Gliksman, 2009) and less likely to recidivate (Gallagher et al., 2014). This suggests that the first month of the program is a critical timeframe in determining long-term outcomes related to graduation and recidivism. Therefore, this finding, coupled with the evidence that being employed or a student also increases the likelihood of graduation, supports the recommendation that drug courts increase their efforts to assist participants in gaining and maintaining employment and/or schooling, which could begin from the beginning of the program. For example, those that are unemployed at their time of admission could be required to apply for jobs and provide evidence of that to the court, be referred to a vocational training program to develop a sustainable skill, or attend a college or university, again to develop a trade that supports sustained employment beyond a participant's time in drug court. Furthermore, drug courts may want to invited employers to be part of the multijudicial team with the goal of increasing employment rates of their participants.

Third, participants who were using opiates as their primary drug of choice were over $80 \%$ less likely to graduate than participants who were using non-opiates as their primary drug of choice. Opiate use disorders have increased in the past decade to epidemic proportions, and one of the most effective approaches to treating opiate use disorders is through the use of medicationassisted treatment (MAT), in combination with counseling that utilizes evidence-based interventions (U.S. Department of Health and Human Services (HHS), Office of the Surgeon 
General, 2016). It is recommended, based on the findings from this study, that drug court participants be evaluated for and, if deemed appropriate, refereed to medical professionals and agencies that can prescribe medication-assisted treatments, such as methadone, Suboxone (buprenorphine and naloxone), and Vivitrol (naltrexone).

It is important to note that the drug court evaluated in this study does currently allow participants to take Vivitrol, but not methadone or Suboxone. However, during the years for this data collection (2010 to 2015), participants were not allowed any medication-assisted treatments. It is also recommended that the drug court not limit medication-assisted treatments to Vivitrol, as methadone and Suboxone have also demonstrated effectiveness in maintaining abstinence from illicit opiates, improved employment outcomes, a reduction in criminal recidivism, to name a few. Suboxone and methadone can be costly, which may be a barrier for some patients to starting and maintaining the medication regiment, and, not every individual with an opiate use disorder is appropriate for medication-assisted treatments. Therefore, it is essential that the drug court coordinate care with experienced, skilled treatment agencies to complete a thorough assessment of participants' needs (Csete \& Catania, 2013). 


\section{References}

Csete, J., \& Catania, H. (2013). Methadone treatment providers' views of drug court policy and practice: A case study of New York state. Harm Reduction Journal, 10(35), 1-9.

Dannerbeck, A., Harris, G., Sundet, P., \& Lloyd, K. (2006). Understanding and responding to racial differences in drug court outcomes. Journal of Ethnicity in Substance Abuse, 5(2), $1-22$.

Gallagher, J. R. (2013a). African American participants' views on racial disparities in drug court outcomes. Journal of Social Work Practice in the Addictions, 13, 143-162.

Gallagher, J. R. (2013b). Drug court graduation rates: Implications for policy advocacy and future research. Alcoholism Treatment Quarterly, 31, 241-253.

Gallagher, J. R. (2014). Predicting criminal recidivism following drug court: Implications for drug court practice and policy advocacy. Journal of Addictions and Offender Counseling, $35,15-29$.

Gallagher, J. R., Ivory, E., Carlton, J., \& Woodward Miller, J. (2014). The impact of an Indiana (United States) drug court on criminal recidivism. Advances in Social Work, 15, 507-521.

Gallagher, J. R., Nordberg, A., Deranek, M. S., Ivory, E., Carlton, J., \& Woodward Miller, J. (2015). Predicting termination from drug court and comparing recidivism patterns: Treating substance use disorders in criminal justice settings. Alcoholism Treatment Quarterly, 33(1), 28-43.

Gill, M. E. (2016). Predictors of drug court client graduation. Journal of Offender Rehabilitation, 55(8), 564-588.

Goldkamp, J. S. (1994). Miami's treatment drug court for felony defendants: Some implications of assessment findings. The Prison Journal, 74(2), 110-166. 
Hickert, A. O., Boyle, S. W., \& Tollefson, D. R. (2009). Factors that predict drug court completion and drop out: Findings from an evaluation of Salt Lake County's adult felony drug court. Journal of Social Service Research, 35(2), 149-162.

International Association of Drug Treatment Courts [IADTC]. (2017). Drug treatment courts worldwide. Retrieved from http://www.nadcp.org/countries

Listwan, S. J., Shaffer, D. K., \& Hartman, J. L. (2009). Combating methamphetamine use in the community: The efficacy of the drug court model. Crime \& Delinquency, 55(4), 627644.

Marlowe, D. B. (2013). Achieving racial and ethnic fairness in drug courts. Court Review, 49, $40-47$.

Mitchell, O., Wilson, D. B., Eggers, A., \& MacKenzie, D. L. (2012). Assessing the effectiveness of drug courts on recidivism: A meta-analytic review of traditional and non-traditional drug courts. Journal of Criminal Justice, 40, 60-71.

Mullany, J. M., \& Peat, B. (2008). Process evaluation of a county drug court: An analysis of descriptors, compliance and outcome-answering some questions while raising others. Criminal Justice Policy Review, 19(4), 491-508.

National Association of Drug Court Professionals [NADCP]. (2004). Defining drug courts: The key components. Retrieved from https://www.ncjrs.gov/pdffiles1/bja/205621.pdf

National Association of Drug Court Professionals [NADCP]. (2017). About NADCP. Retrieved from http://www.nadcp.org/learn/about-nadep

Newton-Taylor, B., Patra, J., \& Gliksman, L. (2009). Toronto drug treatment court: Participant intake characteristics as predictors of "successful" program completion. Journal of Drug Issues, 39, 965-987. 
Orme, J. G., \& Combs-Orme, T. (2009). Multiple regression with discrete dependent variables. New York, NY: Oxford University Press.

Peters, R. H., \& Murrin, M. R. (2000). Effectiveness of treatment-based drug courts in reducing criminal recidivism. Criminal Justice and Behavior, 27(1), 72-96.

Shaffer, D. K. (2011). Looking inside the black box of drug courts: A meta-analytic review. Justice Quarterly, 28, 493-521.

U.S. Department of Health and Human Services (HHS), Office of the Surgeon General. (2016). Facing addiction in America: The surgeon general's report on alcohol, drugs, and health. Washington, DC: HHS. 


\section{Table 1}

Coding Scheme and Descriptive Statistics for Model Variables

\begin{tabular}{|c|c|c|c|c|}
\hline Predictor & Range & Key & M(SD) & $\%$ \\
\hline \multirow[t]{2}{*}{ Drug Court Outcome } & $0-1$ & $0-$ Terminated & & 36.7 \\
\hline & & 1 - Graduated & & 63.3 \\
\hline \multirow{2}{*}{ Gender } & $0-1$ & 0 -Female & & 26.6 \\
\hline & & $1-$ Male & & 73.4 \\
\hline \multirow[t]{2}{*}{ Race/ethnicity } & $0-1$ & 0 - Non-White & & 34.7 \\
\hline & & 1-White & & 65.3 \\
\hline Age & $18-60$ & Age at time of admission (in years) & $30.84(10.48)$ & \\
\hline \multirow{2}{*}{ Education } & $0-1$ & 0 - No high school diploma & & 29.0 \\
\hline & & 1 - High school diploma & & 71.0 \\
\hline \multirow[t]{2}{*}{ Employment Status } & $0-1$ & 0 - Not employed or student at admission & & 49.6 \\
\hline & & 1 - Employed/Student at time of admission & & 50.4 \\
\hline \multirow{2}{*}{ Primary Drug } & $0-1$ & $0-$ Not opiates & & 75.4 \\
\hline & & 1 -Opiates & & 24.6 \\
\hline \multirow[t]{2}{*}{ Mental Health } & $0-1$ & 0 - No mental health diagnosis & & 73.0 \\
\hline & & 1 - Mental health diagnosis & & 27.0 \\
\hline \# of Days & $16-646$ & Number of days between arrest and admission to Drug Court & $85.32(81.73)$ & \\
\hline \multirow[t]{2}{*}{ Criminal History } & $0-1$ & 0 - No previous criminal case prior to current charge & & 80.2 \\
\hline & & 1 - Previous criminal case prior to current charge & & 19.8 \\
\hline \multirow[t]{2}{*}{ First 30 Days } & $0-1$ & 0 - No violation in the first 30 days & & 42.7 \\
\hline & & 1 - Had a violation in the first 30 days & & 57.3 \\
\hline
\end{tabular}


Table 2

Baseline Characteristics by Completion Status

\begin{tabular}{|c|c|c|c|c|}
\hline \multirow[b]{2}{*}{ Demographic Category } & \multicolumn{3}{|c|}{ Completion Status (\% or $\mathrm{M}$ ) } & \multirow[b]{2}{*}{$X^{2}$ or $t$} \\
\hline & $\mathbf{N}$ & $\begin{array}{c}\text { Graduated } \\
(\mathrm{n}=157)\end{array}$ & $\begin{array}{c}\text { Terminated } \\
(\mathrm{n}=91)\end{array}$ & \\
\hline \multicolumn{5}{|l|}{ Gender } \\
\hline Female & 66 & 62.1 & 37.9 & .05 \\
\hline Male & 182 & 63.7 & 36.3 & \\
\hline \multicolumn{5}{|l|}{ Race/ethnicity } \\
\hline Non-White & 86 & 67.4 & 32.6 & .97 \\
\hline White & 162 & 61.1 & 38.9 & \\
\hline Age & & 31.45 & 29.78 & -1.26 \\
\hline \multicolumn{5}{|l|}{ Education } \\
\hline No HS Diploma & 72 & 58.3 & 41.7 & 1.03 \\
\hline HS Diploma & 176 & 65.3 & 34.7 & \\
\hline \multicolumn{5}{|l|}{ Employment Status } \\
\hline Not employed or in school & 123 & 52.0 & 48.0 & $13.35 * * *$ \\
\hline Employed/Student & 125 & 74.4 & 25.6 & \\
\hline \multicolumn{5}{|l|}{ Primary Drug } \\
\hline Not opiates & 208 & 69.7 & 30.3 & $22.78 * * *$ \\
\hline Opiates & 40 & 30.0 & 70.0 & \\
\hline \multicolumn{5}{|l|}{ Mental Health } \\
\hline No MH Diagnosis & 181 & 64.1 & 35.9 & .18 \\
\hline MH Diagnosis & 67 & 61.2 & 38.8 & \\
\hline \# of Days & & 87.45 & 81.66 & -.54 \\
\hline \multicolumn{5}{|l|}{ Previous Case } \\
\hline No previous criminal case & 199 & 66.3 & 33.7 & $3.97 *$ \\
\hline Previous criminal case & 49 & 51.0 & 49.0 & \\
\hline \multicolumn{5}{|l|}{ First 30 Days } \\
\hline No violation in first 30 days & 106 & 70.8 & 29.2 & $4.42 *$ \\
\hline Violation in first 30 days & 142 & 57.7 & 42.3 & \\
\hline
\end{tabular}


Table 3

Hierarchical Logistic Regression Results

\begin{tabular}{|c|c|c|c|c|c|c|c|c|c|c|c|c|}
\hline & \multicolumn{4}{|c|}{ Model One } & \multicolumn{4}{|c|}{ Model Two } & \multicolumn{4}{|c|}{ Model Three } \\
\hline & B & Wald & $\operatorname{Exp}(B)$ & 95\% C.I. & B & Wald & $\operatorname{Exp}(B)$ & 95\% C.I. & B & Wald & $\operatorname{Exp}(B)$ & $95 \%$ C.I. \\
\hline Gender & -.13 & .17 & .88 & $.47-1.65$ & -.10 & .08 & .91 & $.46-1.80$ & -.06 & .32 & .94 & $.47-1.88$ \\
\hline Race/Ethnicity & -.40 & 1.79 & .67 & $.37-1.21$ & -.13 & .16 & .88 & $.47-1.65$ & -.10 & .10 & .91 & $.48-1.70$ \\
\hline Age & .02 & 1.43 & 1.02 & $.99-1.05$ & .00 & .00 & 1.00 & $.97-1.03$ & .00 & .01 & 1.00 & $.97-1.03$ \\
\hline Education & .23 & .58 & 1.26 & $.70-2.28$ & .44 & 1.90 & 1.55 & $.83-2.90$ & .36 & 1.19 & 1.43 & $.75-2.70$ \\
\hline Employment Status & 1.02 & $12.89 * * *$ & 2.77 & $1.59-4.83$ & .89 & $8.75 * *$ & 2.44 & $1.35-4.41$ & .90 & $8.88 * *$ & 2.47 & $1.36-4.46$ \\
\hline Primary Drug & & & & & -1.73 & $15.57 * * *$ & .18 & $.08-.42$ & -1.79 & $16.09 * * *$ & .17 & $.07-.40$ \\
\hline Mental Health & & & & & .28 & .63 & 1.32 & $.66-2.62$ & .27 & .57 & 1.31 & $.65-2.61$ \\
\hline \# of Days & & & & & .00 & .61 & 1.00 & $1.00-1.01$ & .00 & .60 & 1.00 & $1.00-1.01$ \\
\hline Previous Case & & & & & -.17 & .20 & .85 & $.40-1.78$ & -.20 & .27 & .82 & $.39-1.74$ \\
\hline First 30 Days & & & & & & & & & -.78 & $5.05^{*}$ & .51 & $.28-.92$ \\
\hline Block $\chi^{2}$ & $17.42 * *$ & & & & $18.93 * * *$ & & & & $5.21 *$ & & & \\
\hline Model $\chi^{2}$ & $17.42 * *$ & & & & $36.35^{* * *}$ & & & & $41.56^{* * *}$ & & & \\
\hline Nagelkerke $\mathbf{R}^{2}$ & .09 & & & & .19 & & & & .21 & & & \\
\hline$-2 \mathrm{LL}$ & 308.60 & & & & 289.67 & & & & 284.46 & & & \\
\hline
\end{tabular}

$* p \leq .05, * * \mathrm{p} \leq .01, * * * p \leq .001$ 